\title{
CONFIGURAÇÕES ESTRATÉGICAS EM MPES: UMA ANÁLISE DA ATUAÇÃO DE MULHERES EMPREENDEDORAS DO SETOR DE SERVIÇOS DE LONDRINA - PR
}

\author{
STRATEGIC SETTINGS IN MICRO AND SMALL BUSINESS: \\ AN ANALYSIS ON THE PERFORMANCE OF WOMEN \\ ENTREPRENEURS OF SERVICES SECTOR IN LONDRINA - PR
}

Data de submissão: 07/05/2013 Aceite: 26/01/2016

Gabriel Varea Gonçalves ${ }^{1}$ Saulo Fabiano Amâncio Vieira ${ }^{2}$ Gerson Antonio Melatti ${ }^{3}$ Fernando Antonio Prado Gimenez ${ }^{4}$ Letícia Fernandes de Negreiros ${ }^{5}$

\section{RESUMO}

A presente pesquisa busca verificar a existência de diferentes configurações no processo de formação de estratégia em pequenas empresas do setor de serviços de Londrina/PR. Como referencial teórico utilizou-se os estudos de Cochia e Machado da Silva (2004) acerca do contexto ambiental, Miles e Snow (1978) e os quatro tipos de estratégia, Carland, Carland e Hoy $(1992,1998)$ e Inácio e Gimenez (2004) para mensurar o grau empreendedor, e Bailey e Avery (1998)) para a classificação dos tipos estratégicos. Quanto aos procedimentos metodológicos a pesquisa classifica-se como quantitativa, descritiva e exploratória. Realizou-se um censo com as 70 empresas de serviço associadas à CMEG/FECOMERCIO. Quanto aos resultados observou-se que a maioria dos dirigentes dessas empresas tem atitude Empreendedora; que o principal tipo de estratégia competitiva adotado foi a Incremental; que o contexto ambiental das empresas é local; e a dimensão predominante no desenvolvimento da estratégia é a Prospector, ou seja, são empresas que buscam continuamente ampliar a linha de produtos/serviços.

Palavras-chave: estratégia, formulação estratégica, administração de MPEs, empreendedorismo.

\footnotetext{
1 Possui graduação em Administração de Empresas pela Universidade Estadual de Londrina. Londrina. Paraná. Brasil.

E-mail: gavarea@gmail.com

2 Possui graduação em Administração de Empresas pela Universidade Estadual de Londrina, UEL, mestrado em Administração pela Universidade Estadual de Maringá, UEM, doutorado em Administração pela Universidade Nove de Julho, UNINOVE. Atualmente é professor adjunto do curso de Administração da Universidade Estadual de Londrina e do Programa de Mestrado em Administração - PPGA/UEL. Londrina. Paraná. Brasil. E-mail: saulo@uel.br

3 Possui graduação pela Universidade Estadual de Londrina, UEL, especialização em Administração de Recursos Humanos pelo Centro Universitário Filadélfia e mestrado em Administração pela Universidade Estadual de Maringá, UEM. Atualmente é professor assistente do Departamento de Administração da Universidade Estadual de Londrina. Londrina. Paraná. Brasil. E-mail: gmelatti@uel.br

4 Possui graduação em Administração pela Universidade Estadual de Londrina, UEL, especialização em Cinema pela Universidade Tuiuti do Paraná, UTP, mestrado em Administração pela Universidade de São Paulo, USP e doutorado em Doctoral Programme Manchester Business School - University of Manchester, UM, Grã-Bretanha. Atualmente é professor titular do Departamento de Administração Geral e Aplicada da Universidade Federal do Paraná. Curitiba. Paraná. Brasil. E-mail: gimenez@ufpr.br

5 Possui graduação e mestrado em Administração pela Universidade Estadual de Londrina, UEL e doutorado em andamento em Administração pela Universidade Estadual de Maringá, UEM. Maringá. Paraná. Brasil. E-mail: leticia_negreiros@hotmail.com
} 


\begin{abstract}
This research seeks to verify the existence of different settings in the process of strategy formation in small enterprises in the service sector of Londrina/PR. Theoretical framework is based on studies of Cochia and Machado da Silva (2004) about the environmental context, Miles and Snow (1978) about four types of strategy, Carland, Carland and Hoy $(1992,1998)$ and Inácio and Gimenez (2004) to measure the entrepreneur index, and Bailey and Avery (1998) for the classification of strategic types. This research is classified as quantitative, descriptive and exploratory study. It was conducted a censos with the 70 service companies associated with CMEG / FECOMERCIO. The results demonstrate that most of the leaders of these companies have Entrepreneurial attitude, the main type of competitive strategy adopted was incremental, that the environmental context of companies is local, and the dominant dimension in the development of the strategy is the Prospector, in other words, companies are continually seeking to expand the range of products / services.
\end{abstract}

Keywords: strategy. strategic formulation. micro and small businesses. entrepreneurship.

\title{
1 INTRODUÇÃO
}

Conforme o entendimento de Porter (1986) cada organização, que concorre em uma área industrial, possui uma estratégia competitiva, seja ela explícita ou implícita. As estratégias podem ser desenvolvidas de modo explícito através de um planejamento sistêmico e implícito através de atividades e decisões isoladas das várias áreas funcionais da empresa. Para Porter (1986), no entanto, a soma destes métodos departamentais raramente equivale à melhor estratégia.

Atualmente as organizações se utilizam da estratégia para garantir que o processo explícito traga benefícios específicos aos processos da empresa buscando assegurar que as políticas dos departamentos funcionais tenham metas em comum, que conduzam as ações das diversas áreas, para o mesmo foco e objetivo. Assim, o desenvolvimento de uma estratégia competitiva, além de determinar os objetivos e metas, mostra como a empresa estará situada no mercado, qual será sua referência para os consumidores e também engloba outros agentes como os fornecedores, governo e comunidade em geral.

Na visão de Hamel e Prahalad (1995) a humanidade está no limiar de novas revoluções, tão intensas quanto a que deu origem a revolução industrial. Trata-se da revolução ambiental, revolução genética, revolução de materiais, revolução digital e a continuidade da revolução que já está muito presente nas ações do dia-a-dia, a revolução da informação. Portanto as empresas devem levar em conta que o cenário global está mudando e para isso o processo de planejamento estratégico também precisa se adaptar às novas realidades. A estratégia de qualquer empresa deve sempre estar em constante reavaliação e as mudanças necessárias devem ser continuamente implantadas.

Até a década de 1980, o ambiente principal a ser levado em conta no planejamento estratégico era o externo (Hitt, 2008). O modelo de organização de retornos acima da média explicava a causa das estratégias estarem voltadas muito para o ambiente externo. Na atualidade, todavia, é preciso que as novas realidades sejam trazidas para dentro da empresa. Em diferentes períodos um tipo de processo produtivo imperou como a melhor opção estratégica, levando-se em conta o contexto social e cultural de cada época. Dentre elas pode-se citar desde o Fordismo e o Taylorismo, provenientes da América do Norte, até o Toyotismo e o Just-in-time, implantados na administração das companhias japonesas.

A literatura do campo da Administração registra que gerenciar uma grande empresa é completamente diferente do que administrar um empreendimento de tamanho pequeno ou médio. Na avaliação de Porter (1986), quanto menor é a empresa mais importante é a estratégia, porque as empresas menores, ao contrário das gigantes, são mais sensíveis à variação do mercado, e por isso, precisam perceber o ambiente competitivo com maior clareza e rapidez para garantir a sobrevivência nos negócios. 
Ao considerar o contexto do Município de Londrina - PR, os dados da Federação do Comércio do Estado do Paraná [FECOMERCIO-PR] indicam que a cidade conta com 30.355 empresas categorizadas como grandes, médias, pequenas e micro, segundo os critérios estabelecidos pelo Serviço de Apoio às Micro e Pequenas Empresas do Paraná [SEBRAE]. Deste total, $99 \%$ das empresas estão classificadas como micro e pequenas empresas. Dentre estas, 46 \% são atuantes no setor de serviços. Ainda de acordo com a pesquisa da FECOMERCIO - PR, essas empresas são responsáveis por gerar $28,12 \%$ dos empregos formais da cidade de Londrina.

Ciente, portanto, da importância que o segmento das micro e pequenas empresas de serviço em Londrina trazem para o desenvolvimento socioeconômico da cidade e região bem como a relevância que o processo de formação estratégia tem para este perfil de empresa, levanta-se a seguinte questão: quais são as configurações do processo de formação de estratégia em pequenas empresas do setor de serviços de Londrina conduzidas por mulheres?

Assim, para atender as intenções acima apresentadas o objetivo principal da pesquisa busca verificar a existência de diferentes configurações ${ }^{1}$ no processo de formação de estratégia em pequenas empresas do setor de serviços de Londrina conduzidas por mulheres. Foram estabelecidos como objetivos específicos: a) revelar a perspectiva predominante no processo de desenvolvimento de estratégia nas empresas pesquisadas; b) mensurar a atitude empreendedora do principal dirigente dessas organizações; $c$ ) identificar o tipo de estratégia competitiva utilizado; d) identificar o contexto ambiental de referência (local, regional, nacional ou internacional) adotado.

Pelos argumentos aqui elencados, este estudo justifica-se em termos teóricos pelo fato de poder trazer maior disseminação do conhecimento sobre a estratégia, ao combinar quatro arranjos teóricos na interpretação dos dados. Além de tentar revelar a realidade das pequenas empresas do setor de serviços de Londrina- PR, o que provavelmente estimulará o desenvolvimento de novas pesquisas que podem complementá-la, contribuindo para a melhoria do planejamento estratégico e aumentando a competitividade das pequenas empresas.

Em termos práticos, a realização da pesquisa poderá contribuir para identificar o nível de empreendedorismo dos dirigentes locais pesquisados e verificar se o processo estratégico adotado pelas empresas está de acordo com a literatura, além de poder alavancar futuros estudos que possam trazer melhorias para o setor, bem como para levantar novos fatos que possibilitem comparações com outras realidades regionais, nacionais ou internacionais.

\section{REFERENCIAL TEÓRICO}

Como referencial teórico utilizou-se os estudos de desenvolvidos por Cochia e Machado da Silva (2004) para identificar o contexto ambiental de referência, Miles e Snow (1978) para identificar os tipos de estratégia competitiva, Carland, Carland e Hoy $(1992,1998)$ e Inácio e Gimenez (2004) para mensurar o grau empreendedor, e Bailey e Avery (1998) para a classificação das diferentes abordagens (perspectivas) ao processo de formulação de estratégias.

Para Cochia e Machado da Silva (2004) a noção de contexto ambiental de referência implica reconhecer que o contexto ambiental de referência atua como o componente delimitador de um padrão institucionalizado de cognição.

No quadro 1, a seguir, podem-se observar as variáveis que compõem os focos em cada contexto ambiental: internacional, nacional e regional.

\footnotetext{
1 Configuração, neste trabalho, é entendida como uma constelação multidimensional de características conceitualmente distintas que frequentemente ocorrem em conjunto ou ao mesmo tempo (MEYER; TSUI; HININGS, 1993), ou seja, é um emaranhado de fatores que fazem com que a estratégia de uma micro ou pequena empresa seja a escolhida.
} 


\begin{tabular}{|c|c|c|c|}
\hline & Internacional & Nacional & Regional \\
\hline Objetivo & $\begin{array}{l}\text { Consolidar ou ampliar } \\
\text { a participação no mer- } \\
\text { cado internacional }\end{array}$ & $\begin{array}{c}\text { Consolidar ou ampliar a } \\
\text { participação no mercado } \\
\text { nacional }\end{array}$ & $\begin{array}{l}\text { Consolidar ou ampliar a partici- } \\
\text { pação no mercado regional }\end{array}$ \\
\hline Perspectiva & Internacional & Nacional & Regional \\
\hline $\begin{array}{l}\text { Mercado Con- } \\
\text { sumidor }\end{array}$ & $\begin{array}{l}\text { Padrão de consumo } \\
\text { internacional }\end{array}$ & $\begin{array}{l}\text { Padrão de consumo nacio- } \\
\text { nal } \\
\text { Adaptação às novas faixas } \\
\text { de renda }\end{array}$ & Padrão de consumo regional \\
\hline Lógica de ação & $\begin{array}{c}\text { Globalização } \\
\text { Modernização } \\
\text { Expansão comercial } \\
\text { Flexibilidade } \\
\text { Rapidez } \\
\text { Inovação } \\
\text { Proatividade }\end{array}$ & $\begin{array}{c}\text { Reação } \\
\text { Imitação } \\
\text { Adaptação às novas ten- } \\
\text { dências e às oscilações de } \\
\text { consumo } \\
\text { Reestruturação da estrutura } \\
\text { produtiva }\end{array}$ & $\begin{array}{c}\text { Reação } \\
\text { Imitação } \\
\text { Adaptação } \\
\text { Reestruturação }\end{array}$ \\
\hline $\begin{array}{l}\text { Fator deter- } \\
\text { minante de } \\
\text { participação no } \\
\text { mercado }\end{array}$ & Qualidade & Custo de produção & $\begin{array}{l}\text { Custo de produção } \\
\text { Preço dos produtos }\end{array}$ \\
\hline $\begin{array}{l}\text { Bases da com- } \\
\text { petitividade }\end{array}$ & $\begin{array}{c}\text { Inovação } \\
\text { Qualidade } \\
\text { Flexibilidade } \\
\text { Integração da cadeia } \\
\text { produtiva }\end{array}$ & $\begin{array}{c}\text { Investimento em tecnologia } \\
\text { e programas de qualidade e } \\
\text { produtividade } \\
\text { Flexibilização da produção } \\
\text { Capacitação de recursos } \\
\text { humanos } \\
\text { Diferenciação da linha de } \\
\text { produtos (faixas de renda) }\end{array}$ & $\begin{array}{c}\text { Atração de investimentos pro- } \\
\text { dutivos } \\
\text { Investimentos em infra- } \\
\text { estrutura (transporte, energia e } \\
\text { telecomunicações) } \\
\text { Qualidade } \\
\text { Modernização e capacitação } \\
\text { da indústria }\end{array}$ \\
\hline Tecnologia & $\begin{array}{l}\text { Desenvolvimento de } \\
\text { tecnologia } \\
\text { Formação de parce- } \\
\text { rias }\end{array}$ & Aquisição de tecnologia & Aquisição de tecnologia \\
\hline Qualidade & Requisito essencial & $\begin{array}{l}\text { Atendimento a padrões } \\
\quad \text { exigidos } \\
\text { Diferencial competitivo }\end{array}$ & Requisito de consumo \\
\hline Papel do Estado & $\begin{array}{c}\text { Promoção de } \\
\text { incentivo ao comércio } \\
\text { exterior, incentivan- } \\
\text { do as exportações, } \\
\text { combatendo práticas } \\
\text { ilegais de comércio e } \\
\text { realizando acordos in- } \\
\text { ternacionais }\end{array}$ & $\begin{array}{c}\text { Redução dos entraves à } \\
\text { concorrência na indústria } \\
\text { nacional, facilitando o } \\
\text { acesso ao crédito, reduzin- } \\
\text { do a tributação, promoven- } \\
\text { do o crescimento e a estabi- } \\
\text { lidade econômica }\end{array}$ & $\begin{array}{l}\text { Estímulo à competitividade da } \\
\text { indústria em nível regional, } \\
\text { promovendo o crescimento e o } \\
\text { desenvolvimento econômico }\end{array}$ \\
\hline
\end{tabular}

Quadro 1 - Contexto Ambiental

Fonte: Cochia e Machado da Silva (2004) 
Analisando os dados acima se pode observar que cada contexto ambiental está voltado para uma diferente forma de atuação e definição de estratégia empresarial. Cada empresa, independentemente do seu tamanho e tipo de atividade realizada, está voltada para um dos contextos citados acima, e é nesse contexto que a organização concentra a sua atuação, determinando as estratégias que serão utilizadas.

É possível acrescentar também mais um contexto, o de empresa local, ou seja, aquela em que a organização está muito mais voltada para ações que englobem apenas a cidade ou comunidade em que está inserida, tendo uma atuação mais restrita. Tais fatores levam essas empresas a buscarem apoio governamental local, exigindo que o poder público promova melhoras pontuais, através de investimentos, deduções, incentivos e capacitação para o setor (AMÂNCIOVIEIRA, NEGREIROS, MELATTI, GIMENEZ, 2013).

O contexto considerado como regional, na classificação proposta por Cochia e Machado da Silva (2004) possui como lógica de ação a reação, a imitação, a adaptação e a reestruturação. As empresas que integram esse grupo possuem o seu escopo de atuação e concorrência limitando-se ao Estado do Paraná e suas regiões limítrofes. Sua administração é totalmente voltada para consolidar ou ampliar a sua atuação nesse território de mercado.

As empresas integrantes do mercado nacional são aquelas voltadas para um mercado mais amplo e que abrange todo o país, e se orientam estrategicamente de acordo com os valores desse contexto. Costumam investir em design e em aperfeiçoar seus produtos. A competição é baseada em preços baixos, promoção e qualidade dos produtos. Essas empresas também detêm características inovadoras e procuram sempre estar atualizadas em relação ao mercado nacional (Cochia \& Machado da Silva, 2004).

Para complementar as ideias de Cochia e Machado da Silva (2004), foram também utilizados os estudos de Miles e Snow (1987) que categorizam as estratégias competitivas em: 1. Defensiva; 2. Prospectora; 3. Analítica; 4. Reativa.

Estratégia Defensiva: as empresas, seguindo esta estratégia, procuram localizar e manter uma linha de produto/serviços relativamente estável. Seu foco concentra-se em uma gama de produtos/serviços mais limitada do que seus concorrentes e tentam proteger seus domínios, através da oferta de produtos com melhor qualidade, serviços superiores, e/ou menores preços. Não procuram estar entre os líderes, restringindo-se àquilo que sabem fazer muito bem.

Estratégia Prospectora: as organizações que adotam esta estratégia estão continuamente ampliando sua linha de produtos/serviços. Enfatizam a importância de oferecer novos produtos/serviços em uma área de mercado relativamente mais ampla. Valorizam serem as primeiras a oferecer novos produtos, mesmo que todos os esforços não se mostrem altamente lucrativos.

Estratégia Analítica: as empresas que seguem esta estratégia tentam manter uma linha limitada de produtos/serviços, relativamente estável e ao mesmo tempo buscam adicionar um ou mais novos produtos /serviços que foram bem sucedidos em outras empresas do setor. Em muitos aspectos é uma posição intermediaria entre as estratégias defensivas e prospectora.

Estratégia Reativa: ao adotar uma estratégia reativa a empresa exibe um comportamento mais inconsistente do que os outros tipos. É uma espécie de não estratégia. Não arrisca em novos produtos/serviços a não ser quando ameaçada por competidores. A abordagem típica é "esperar para ver" e responder somente quando forçada por pressões competitivas para evitar a perda de clientes importantes e / ou manter lucratividade.

Complementarmente, outros autores no campo da estratégia buscam classificar o estilo de comportamento adotado pelos empreendedores baseado em suas atitudes e em suas decisões. Neste sentido, apresenta-se mais uma teoria de classificação para qual o tipo de pensamen- 
to e amplitude que se encaixam os empreendedores, ou seja, definir qual o tipo de empreendedor das empresas, para complementar as outras correntes teóricas anteriormente destacadas .

De acordo com Inácio e Gimenez (2004), que se basearam nos estudos de Carland, Carland e Hoy $(1992$; 1998) para desenvolver suas teorias o empreendedorismo é um processo complexo baseado em diversas variáveis, que levam ao ato de empreender. As variáveis mais presentes são: sociais (mobilidade social, cultura, sociedade); econômicas (incentivos de mercado, políticas públicas, capital de risco); e psicológicas. Entres essas características atribuídas ao empreendedor aquelas mais citadas são: necessidade de realização, propensão ao risco, criatividade, visão, alta energia, postura estratégica e autoconfiança. No entendimento dessa teoria o empreendedor é alguém que estabelece um negócio objetivando lucro e crescimento, através de um comportamento inovador e adotando uma postura estratégica (INÁCIO; GIMENEZ, 2004).

Para Inácio e Gimenez (2004) é difícil estabelecer um sistema que quantifique o nível de empreendedorismo, por ser uma variável subjetiva. Dentre vários métodos existentes destaca-se a proposta do teste Carland Entrepreneurship Index [CEI] de Carland, Carland e Hoy (1992, 1998), instrumento de medição onde os pesquisadores definiram que o empreendedorismo é uma função composta por quatro elementos: 1. traços de personalidade; 2. inovação; 3. propensão ao risco; 4. postura estratégica.

Através desses quatro elementos é possível classificar os empreendedores quanto ao seu pensamento estratégico: (a): Macroempreendedores: definidos como aqueles que enxergam o seu negócio como um meio de mudar o setor e ser uma força dominante. Para esse grupo o sucesso é medido através do tamanho do seu negócio. (b): Microempreendedores: estabelecidos como aqueles que criam um negócio que nunca crescerá, mas que se torna uma referência na comunidade ou cidade em que está localizado. Seu negócio é uma forma de fonte de renda primária para o sustento familiar, e não aspiram tornar-se mais do que isso. (c): Empreendedores: situados entre as duas faixas apresentadas anteriormente, eles apresentam tanto aspectos de Micro quanto de Macroempreendedores, e sua estratégia engloba esses dois universos em aspectos diferentes. Cada decisão é baseada em uma diferente faixa de classificação, o que o torno misto.

O questionário montado para o teste $C E I$ é um questionário de auto resposta com trinta e três frases afirmativas em pares, no formato de escolha forçada, ou seja, o indivíduo deve optar necessariamente por uma entre duas opções. A cada resposta escolhida é atribuída uma pontuação, que somada ao fim do teste, irá ser classificada entre uma das três faixas de empreendedores acima citadas, através da seguinte escala: microempreendedor ( 0 a 15 pontos); empreendedor ( 16 a 25 pontos); e macroempreendedor ( 26 a 33 pontos).

Outro relevante trabalho que complementa os já citados é o de Bailey e Avery (1998) propõem um método para verificar qual o tipo de estratégia adotada pelos empreendedores, entre seis grupos diferentes de tipos de pensamento.

Uma pesquisa foi desenvolvida para se chegar a classificação entre os grupos: no questionário o respondente deve selecionar uma nota de 1 a 7, para cada item, de acordo com a importância para o seu negócio, sendo 1 discordo totalmente e 7 concordo totalmente. De acordo com a pontuação obtida, os empreendedores podem enxergar o processo de formulação de estratégias sob 6 perspectivas: 1.Planejamento; 2 Incremental; 3. Política; 4. Cultural; 5. Visionário; 6. Escolha Forçada.

Sobre a perspectiva do planejamento Bailey e Avery (1998) ressaltam que a formulação estratégica é um procedimento intencional que envolve uma série de procedimentos lógicos. Metas e objetivos bem definidos são delineados pela alta cúpula da organização. A organização e o seu ambiente, tanto externo quanto interno, são analisados sistematicamente. A tomada de decisão com a finalidade de maximizar as entradas em relação aos objetivos é a que melhor se encaixa nos critérios de seleção definidos. 
Do ponto de vista da perspectiva incremental, a estratégia é formulada propositadamente e é intencional, mas pela sua complexidade os administradores não conseguem analisar todas as variáveis do ambiente nem estabelecer objetivos precisos. Mesmo assim, os empreendedores conseguem ter uma visão de onde querem que a organização esteja, e tentam seguir um caminho para atingir essa perspectiva, de um modo evolucionário, buscando assegurar um forte foco no negócio. Nesse processo a estratégia é desenvolvida através de feedbacks de fases anteriores, onde problema e solução devem ser redefinidos ou novamente desenvolvidos. Os empresários aceitam a incerteza do ambiente à medida que descobrem não serem capazes de prever quando o mesmo irá mudar. Por esse motivo, eles buscam ser sensitivos quanto ao ambiente através de pesquisas constantes, avaliação e também do aprender fazendo.

Através de uma perspectiva política, Bailey e Avery (1998) descrevem a empresa como uma entidade política e, como tal, as estratégias são suscetíveis às influências dos stakeholders. Os stakeholders e os interesses do grupo têm grandes chances de terem diferentes preocupações e tentam alcançar seus próprios fins e objetivos. Coalisões e parcerias são formadas para perseguir objetivos comuns e para apoiar diferentes opções estratégicas. Essas opções são buscadas não só para obter ganhos para a empresa, mas também para os stakeholders, através de barganha, negociação, e compromisso com resultados.

A estratégia que as organizações adotam também pode ser influenciada por aspectos culturais. Essa é a ideia principal da perspectiva cultural. O entendimento e compartilhamento dos valores, virtudes e crenças organizacionais permitem que a empresa e seu ambiente sejam compreendidos. Tais situações favorecem que as novas nuances do ambiente sejam percebidas de um modo único. Os administradores são fortemente influenciados por essas crenças e virtudes e isso os influencia na hora de traçar a estratégia do negócio. Elas também formam um guia de comportamento e caminhos a serem seguidos para a correta tomada de decisões.

A perspectiva visionária para Bailey e Avery (1998), tem como base a teoria de que a estratégia que uma empresa adota também pode ser vista como uma visão que representa um estado futuro desejado para a organização. Essa visão que é primeiramente associada com um indivíduo, ou pequeno grupo, direciona a estratégia e providência um quadro de trabalho, descrição de atividades, para a tomada de decisões estratégicas.

Por fim, entende-se por perspectiva da escolha forçada o fato dos administradores de uma organização terem pouco ou nenhum controle sobre a escolha das estratégias que utilizam. Fatores no ambiente direcionam a organização para um caminho que encoraja, e até determina, a adoção de estruturas organizacionais e atividades que se encaixam nesse ambiente. Essas variáveis ambientais reduzem o nível de escolha intencional de uma estratégia e limitam o poder dos tomadores de decisões.

Depois de verificar essas propostas de classificações estratégicas e de posicionamento de empreendedores, torna-se possível buscar semelhanças entre elas e identificar que algumas variáveis possuem bastante similaridade se observadas no detalhe. Pode-se ainda verificar similaridades entre as propostas apresentadas pelos autores, que aparecem com nomenclaturas diferentes.

\section{PROCEDIMENTOS METODOLÓGICOS}

A presente pesquisa, quanto ao seu delineamento, classifica-se como uma pesquisa quantitativa, descritiva e exploratória.

Quantitativa, por apresentar um questionário fechado que possibilita a análise numérica dos dados levantados. 
A primeira razão para se conduzir uma Pesquisa Quantitativa é descobrir quantas pessoas de uma determinada população compartilham uma característica ou um grupo de características. Ela é especialmente projetada para gerar medidas precisas e confiáveis que permitam uma análise estatística (Gil, 2002 p. 75).

Descritiva, pois busca descobrir o perfil, o quanto e o que as mulheres gestoras de micro e pequenas empresas do setor de serviços da cidade de Londrina - PR estão utilizando-se de planejamento estratégico. A pesquisa também é considerada exploratória pois tem como objetivo, desenvolver uma hipótese sobre a questão da utilização de métodos estratégicos nas micro e pequenas empresas de serviços em Londrina, o que pode gerar futuras pesquisas sobre o tema.

Considerando que a pesquisa buscou analisar mulheres empreendedoras da área de serviços, foi levantado os dados pelos autores junto a Câmara das Mulheres Empreendedoras e Gestoras de Londrina (CMEG) (2011), onde estavam cadastradas 70 (setenta) micro ou pequenas empresas do setor de serviços da cidade de Londrina. Portanto o método utilizado para a pesquisa foi o censo, onde todas as empresas filiadas são classificadas pelo SEBRAE (2000) como micro e pequenas empresas por contarem com até 49 empregados. A CMEG da FECOMERCIO é um órgão executivo, coordenado pela Federação, criado para apoiar e defender os interesses econômicos e estimular a responsabilidade social, ambiental e cultural das empresas do comércio de bens, serviços e turismo (FECOMERCIO, 2011). Sua missão segundo a FECOMERCIO (2011) é estabelecer um fórum de discussão entre as Mulheres Empreendedoras e Gestoras de Negócios, integrando-as ao Sistema FECOMERCIO, desenvolvendo ações e projetos que atendam as suas necessidades profissionais e empresariais, através de cursos, treinamento de funcionários, consultorias, dentre outros, para possibilitar uma maior disseminação técnicas de gestão.

Os sujeitos de pesquisa foram mulheres empresárias, proprietárias ou sócias-gerentes das empresas participantes. Inicialmente foi realizado o contato com a presidente da CEMG para solicitação de autorização para realizar a pesquisa. Autorizado, a coleta de dados ocorreu durante as reuniões realizadas pela CMEG nos meses de julho e agosto de 2011.

Para a coleta de dados utilizou-se quatro instrumentos, a saber:

- O primeiro instrumento originou-se no trabalho de Cochia e Machado da Silva (2004) e diz respeito ao contexto de referência que a empresa de comércio reporta-se na tomada de decisões. O contexto de referência das empresas será identificado pela aplicação de um questionário que procura identificar o principal foco das organizações.

- O segundo instrumento procura identificar a estratégia competitiva que será adotada, de acordo com o modelo de Miles e Snow (1978), adotando-se o instrumento desenvolvido por Conant, Mokwa e Varadarajan (1990) que é composto por 11 questões. A análise das respostas permite indicar o perfil estratégico das companhias, identificando aspectos competitivos defensivos, prospectores, analíticos ou reativos.

- O terceiro instrumento busca aferir o índice Carland Entrepeunership-Index CEI, na versão em português (Inácio \& Gimenez, 2004). O CEI consiste de um questionário de auto-resposta contendo trinta e três frases afirmativas em pares, no formato de escolha forçada.

- E finalmente para avaliar o desenvolvimento estratégico das empresas de comércio será adotado o Questionário de Desenvolvimento de Estratégia [QDE] proposto por Bailey e Avery (1998). O QDE é composto por 36 afirmativas que correspondem aos seis diferentes aspectos relacionados ao desenvolvimento estratégico. 
Para análise dos dados foram respeitadas as premissas de cada um dos instrumentos utilizados conforme descrito na seção seguinte.

\section{APRESENTAÇÃO E ANÁLISE DOS DADOS}

Em relação ao primeiro instrumento de pesquisa, buscou-se estabelecer o tipo de visão que as empresárias possuem a respeito do seu negócio e qual seria o contexto ambiental que consideram mais afetar a forma como interpretam seu mercado e mais especificamente a sua empresa. Além disso, foram levantados os tipos de estratégia que as mesmas buscam seguir e acreditam influenciar seu público-alvo. As opções envolviam uma interdependência do negócio com uma visão global, nacional, regional ou local, baseada na teoria sobre o ambiente, a interpretação e estratégia das organizações, apresentadas no estudo de Cochia e Machado da Silva (2004).

Constatou-se que a maioria (69\%) empresas se enquadra no contexto de ambiente local, o que demonstra que essas empresas são fortemente influenciadas pelas mudanças da cidade, estando bem voltadas para esse público. Essas empresas apresentam como característica estarem muito mais voltadas para ações que englobam apenas a cidade ou comunidade em que estão localizadas. Verificou-se que $13 \%$ das empresas atuam num contexto de referencia estratégica regional, $18 \%$ nacional e nenhuma empresa apresentou contexto de referência internacional

No que se refere ao segundo instrumento de pesquisa, elaborado segundo a tipologia proposta por Miles e Snow (1978), também presente no trabalho de Conant, Mokwa e Varadarajan (1990), buscou-se identificar o tipo de estratégia adotado pelas organizações, dentre os critérios reativo, defensor, prospector e analítico. Os dados estão representados no Gráfico 1, a seguir:

Gráfico 1 - Análise do Perfil Estratégico - Miles e Snow (1971)

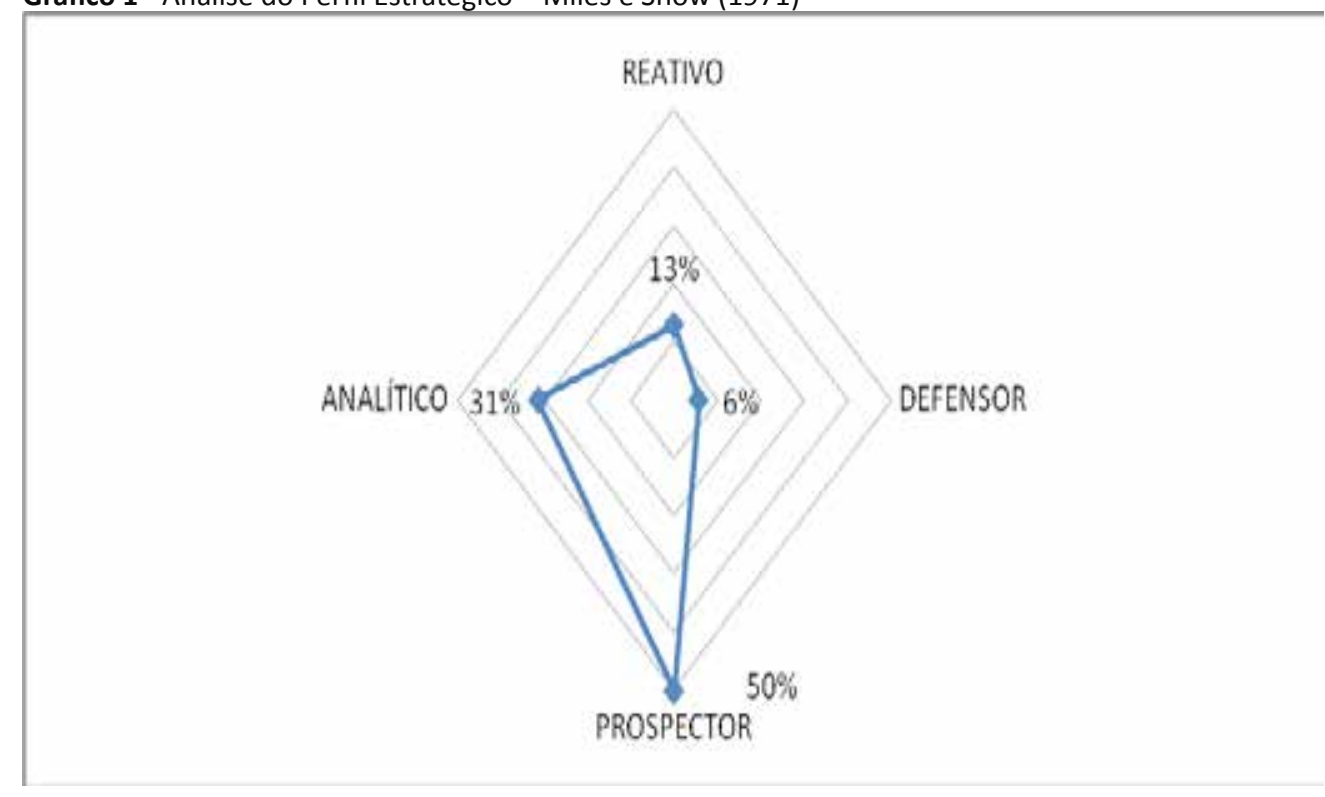

Fonte: autores da pesquisa

De acordo com o Gráfico 1, tornou-se possível observar que 50\% das empresas adotam a estratégia prospectora: estão continuamente ampliando sua linha de produtos/serviços, enfatizam a importância de oferecer novos produtos/serviços em uma área de mercado relativamente mais ampla. Valorizam ser as primeiras a oferecer novos produtos, mesmo que todos os esforços não se mostrem altamente lucrativos. 
No grupo do perfil analítico, encontram-se $31 \%$ das empresas respondentes, que buscam uma linha limitada de serviços, relativamente estável e ao mesmo tempo tentam adicionar um ou mais novos serviços que foram bem sucedidos em outras empresas do setor. Isso pode ser visto como uma posição intermediária entre as estratégias defensivas e prospectora.

As empresas que não costumam arriscar em novos serviços a não ser quando são ameaçadas por competidores, são as de perfil reativo, que nesta pesquisa representam $13 \%$. A abordagem típica desses estabelecimentos é esperar para ver, e responder somente quando forçados por pressões competitivas para evitar a perda de clientes importantes ou manter a sua lucratividade.

Observou-se que $6 \%$ das empresas restantes foram consideradas como adotantes da estratégia defensiva, sendo essas empresas as que procuram localizar e manter uma linha de serviços relativamente estável. Seu foco concentra-se em um leque de serviços mais limitado do que seus concorrentes e tentam proteger seu domínio, através da oferta de produtos com melhor qualidade, serviços superiores, e/ou menores preços. Seu objetivo não é estar entre os lideres do setor, restringindo-se àquilo que sabe fazer tão bem, ou melhor, que fazem melhor do que os concorrentes.

Estes achados que se referem ao perfil estratégico das pequenas empresas de serviço geridas por mulheres em Londrina condizem e mantém porcentagens muito semelhantes aos resultados de outras pesquisa (SOARES, TEIXEIRA, PELISSARI, 2011) aplicada no setor hoteleiro de Florianópolis que também fez uso da tipologia de Miles e Snow (1978).

A seguir são apresentados os resultados da aplicação do terceiro instrumento de pesquisa, o teste de perfil empreendedor CEI.

Na tabela 1 pode-se observar além do percentual, o número absoluto de respostas em cada uma das escalas referentes ao tipo de empreendedor resultantes da aplicação do CEI.

Tabela 1 - Análise do perfil empreendedor

\begin{tabular}{c|c|c|c}
\hline ESCALA DE PONTOS & DEFINIÇÃO DO PERFIL & FREQUÊNCIA & $\%$ \\
\hline 0 a 15 & Microempreendedor & 21 & 30 \\
\hline 16 a 25 & Empreendedor & 49 & 70 \\
\hline 26 a 33 & Macroempreendedor & 0 & 0 \\
\hline
\end{tabular}

Fonte: autores da pesquisa

Observando-se os dados levantados nota-se que no grupo de mulheres empreendedoras estudado, a maior parte (70 \%) das respondentes se encaixa no perfil de Empreendedores. Classificadas como Microempreendedores situaram-se 30\% das empresárias consultadas; são aquelas que criam um negócio que não crescerá muito, mas que se torna uma referência na comunidade ou cidade em que está localizado. Esse negócio é uma forma de fonte de renda primária para o sustento familiar, e o empreendedor não aspira tornar-se maior do que isso; ao contrário do Macroempreendedor, em que o seu negócio é uma parte muito importante na sua vida, mesmo não sendo o motivo a principal dela.

Constatou-se que nenhuma das empreendedoras pesquisadas apresentou o perfil de Macroempreendedor, que segundo a definição apresentada é aquele que observa seu empreendimento como um meio de mudar o setor e ser uma força competitiva dominante. Para esse grupo o sucesso é mensurado através do tamanho do seu negócio.

Como última unidade de análise e completando as intenções deste estudo, após a aplicação do instrumento de pesquisa utilizou-se a teoria de Bailey e Avery (1998) de acordo com as seis perspectivas da estratégia aplicada, conforme demonstrada no gráfico 2 : 
Gráfico 2 - Perspectivas Estratégicas

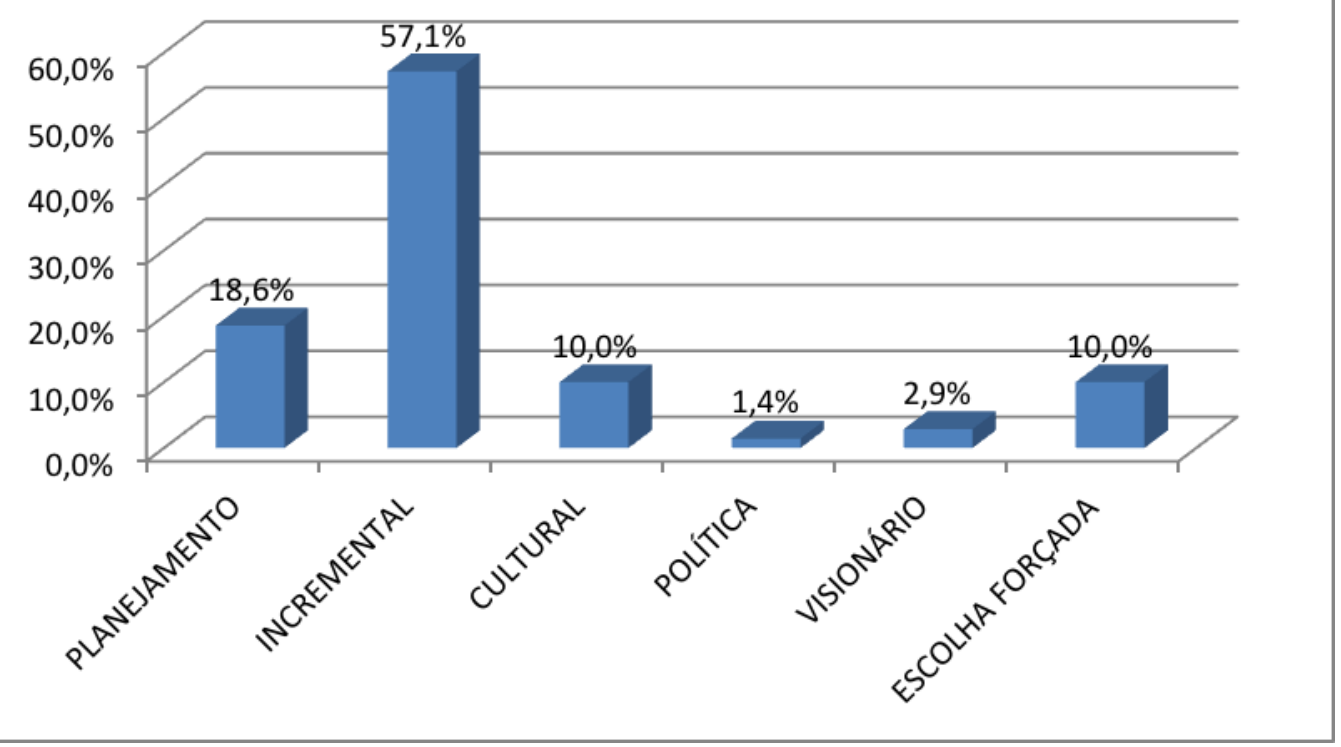

Fonte: autores da pesquisa

Verificou-se que a principal tipologia de estratégia apresentada pelas empresas pesquisadas é a perspectiva Incremental, com uma grande diferença percentual sobre as outras tal tipo estratégico envolve $57,1 \%$ das respostas. A partir do ponto de vista da perspectiva incremental, a estratégia é formulada propositadamente e é intencional, mas pela sua complexidade os gestores não conseguem analisar todas as variáveis do ambiente e nem estabelecer objetivos precisos. Nesse processo a estratégia é desenvolvida através de feedbacks de fases anteriores., no qual problema e solução devem ser redefinidos ou novamente desenvolvidos.

Englobando 18,6\% estão os Planejadores, para os quais a formulação estratégica é um procedimento intencional que envolve uma série de procedimentos lógicos com metas bem delineadas. A perspectiva estratégica Cultural está presente em 10\% das empresas, cujos gestores são fortemente influenciados por essas crenças e virtudes e isso os qualifica no momento de traçar as estratégias do negócio.

Com o índice de 2,9\% encontra-se a perspectiva Visionária. Empreendedores desse grupo tem como base o pensamento de que a estratégia que uma empresa adota, também pode ser vista como uma visão que representa um estado futuro desejado.

Já a perspectiva de Escolha Forçada, com o percentual 10\%, preconiza uma situação onde os gestores possuem pouco ou nenhum controle sobre a escolha das estratégias que utilizam, pois são os fatores ambientais que direcionam a organização. Por fim, com apenas $1,4 \%$ do grupo constatou-se a estratégia observada como perspectiva Política, sendo as estratégias são suscetíveis às influências dos stakeholders. A partir dos dados coletados e considerando que as teorias estudadas se complementam, tornou-se possível estabelecer o perfil das micro e pequenas empresas do setor de serviços e das suas dirigentes.

$O$ contexto ambiental definido domo Local foi tido como predominante junto às empresas, e através da tabela 2 , pode-se verificar qual a dimensão do processo de desenvolvimento da estratégia as mesmas utilizam. 
Tabela 2 - Análise Combinada: Contexto e perfil estratégico

\begin{tabular}{c|c|c}
\hline CLASSIFICAÇÃO & FREQUÊNCIA & \% \\
\hline Local - Defensor & 4 & $8 \%$ \\
\hline Local - Prospector & 22 & $46 \%$ \\
\hline Local - Reativo & 9 & $19 \%$ \\
\hline Local - Analítico & 13 & $27 \%$ \\
\hline
\end{tabular}

Fonte: autores da pesquisa

Foi possível inferir que a maioria das empresas está voltada para o contexto ambiental Local e possuem como dimensão predominante no processo de formulação da estratégia o perfil de Prospectores (46\%). Isso mostra que essas empresas estão muito voltadas a trazer novidades e novos serviços para a população local, buscando serem sempre as primeiras a oferecer esses serviços ao público local.

Após a constatação que a maioria das empresas ficou categorizada como contexto Local e perfil Prospector, buscou-se levantar o relacionamento do aspecto contexto com a atitude empreendedora do principal dirigente da empresa, que está representada na Tabela 3.

Tabela 3 - Análise Combinada: Contexto $X$ atitude empreendedora

\begin{tabular}{c|c|c}
\hline CLASSIFICAÇÃO & FREQUÊNCIA & $\%$ \\
\hline Local - Prospector - Microempreendedor & 4 & $18 \%$ \\
\hline Local - Prospector - Empreendedor & 18 & $82 \%$ \\
\hline
\end{tabular}

Fonte: autores da pesquisa

Analisando-se os dados da tabela 3, observa-se que além de buscarem ser inovadoras no mercado local, as empreendedoras pesquisadas possuem tanto aspectos relacionados ao perfil de Micro quanto de Macroempreendedores, e sua estratégia engloba esses dois universos em aspectos diferentes.

Por fim, inclui-se nas variáveis contexto ambiental e perfil estratégico, apresentadas nas tabelas 2 e 3, o comportamento empreendedor das respondentes e as perspectivas estratégicas das empresas. A tabela 4 relaciona essas variáveis:

Tabela 4 - Análise Combinada: Contexto X Perfil estratégico X Perfil empreendedor X Perspectivas estratégicas

\begin{tabular}{c|c|c}
\hline CLASSIFICAÇÃO & FREQUENCIA & $\%$ \\
\hline Local-Prospector-Medio-Planejamento & 5 & $28 \%$ \\
\hline Local-Prospector-Medio-Incremental & 11 & $61 \%$ \\
\hline Local-Prospector-Medio-Cultural & 1 & $6 \%$ \\
\hline Local-Prospector-Medio-Política & 0 & $0 \%$ \\
\hline Local-Prospector-Medio-Visionário & 1 & $6 \%$ \\
\hline Local-Prospector-Medio-Escolha Forçada & 0 & $0 \%$ \\
\hline
\end{tabular}

Fonte: autores da pesquisa

Com o tratamento dos dados tornou-se possível constatar ainda que a característica mais marcante das micro e pequenas empresas de serviços da Câmara das Mulheres Empreendedoras e Gestoras de Londrina - PR é serem administradas por gestores com perfil de micro e empreendedores - considerados médios empreendedores - e terem como foco a inovação no mercado local. Essas empreendedoras possuem o perfil categorizado como Incremental, ou seja, os gestores não conseguem analisar todas as variáveis do ambiente nem estabelecer objetivos precisos, mas a estratégia é formulada propositadamente e é intencional. 
Através da presente análise foi então possível verificar, definir e exemplificar: o contexto ambiental em que estão inseridas essas empresas; a dimensão no processo de desenvolvimento de estratégia nesses empreendimentos; a atitude empreendedora dos gestores dessas empresas; e os tipos de estratégia adotados na administração.

\section{CONSIDERAÇÕES FINAIS}

As teorias de Cochia e Machado da Silva (2004), Miles e Snow (1987), Inácio e Gimenez (2004) - baseados em Carland, Carland e Hoy $(1992,1998)$ - e Bailey e Avery $(1998)$ consideradas neste trabalhado mostraram-se complementares, possibilitando uma melhor análise do ambiente estratégico em que os negócios estão alocados. Sendo assim, esses estudos possibilitaram a criação de um método prático e eficaz para determinar quais variáveis estratégicas mais influenciam as empresas e de que modo elas respondem ao ambiente externo.

Desta forma, utilizando-se desta complementaridade foi possível verificar a existência de diferentes configurações no processo de formação de estratégia em pequenas empresas do setor de serviços de Londrina/PR que são conduzidas por mulheres.

Nesse sentido, verificou-se que o contexto ambiental de referencia das empresas pesquisadas e o Local (69\%), ou seja, é influenciada diretamente pelos costumes e valores locais, buscando serem as melhores no ambiente em que estão inseridas. Destaca-se ainda que nenhuma dessas micro e pequenas empresas de serviços, estão inseridas em um contexto ambiental Internacional. Tal fato possa ser justificado por Londrina ser um polo regional de agricultura e pecuária, sem tradição industrial que apenas na ultima década passou a contar com empresas do setor de tecnologia.

Ao se mensurar a atitude empreendedora do principal dirigente dessas pequenas empresas levantou-se que a maior parte é tida como Empreendedora (70\%), enquanto que $30 \%$ podem ser classificadas como Microempreendedoras. Os resultados demonstram que nenhum dos pesquisados pode ser considerado como Macroempreendedor, de acordo com o instrumento utilizado. Pode-se inferir que nenhuma das empreendedoras foi categorizada como Macroempreendedora tendo em vista as mudanças no mundo do trabalho, onde a mulher recentemente passou a ocupar o espaço nas organizações e em cargos de direção. Também pode-se interpretar que no campo do empreendedorismo as mulheres continuam enfrentando barreiras e situam-se no setor de serviços.

Quanto a dimensão predominante no desenvolvimento da estratégia nessas empresas, verificou-se que a Prospectora foi a mais presente (50\%), o que evidencia uma tendência a ampliar constantemente os serviços, enfatizar a importância de oferecê-los ao mercado buscando o aumento da abrangência territorial, bem como colocando alterações importantes no portfólio da prestação de serviços, confirmando as características inerentes do gênero feminino.

Finalizando, ao se levantar o principal tipo de estratégia competitiva adotado pelas empresas, identificou-se a perspectiva Incremental $(57,1 \%)$, onde tem-se que a mesma é formulada de forma intencional em um ambiente complexo. Nessa perspectiva estratégica, embora sem conseguir controlar as variáveis ambientais, as empreendedoras definem e alcançam uma visão de futuro. Isso pode ser explicado pelo grande envolvimento na condução do próprio negócio.

Como limitação o estudo se restringe a um número reduzido de casos analisados. Ademais, outras características que podem intervir no processo de formulação estratégica poderiam ser abordadas em pesquisas futuras, como o caso do setor do negócio, da vocação técnica do empreendedor, da missão e visão da organização (BERTÉ; RODRIGUES; ALMEIDA, 2008), entre outras.

No entanto, apesar das limitações, este artigo apresenta indicações de que há diferentes configurações no processo de formação de estratégia em pequenas empresas do setor de 
serviços de Londrina, o que poderá ser confrontado em estudos complementares nos setores de comércio e indústria da mesma região ou locais com características semelhantes. Ademais, estudos qualitativos que abordassem o processo de formação da estratégia, como o de Gomes, Muniz, Dias e Gonçalves (2012), complementados pelos quarto arranjos teóricos propostos pelo trabalho seriam de grande valia para o aprofundamento do tema.

Por fim, nota-se que este estudo contribuiu teoricamente ao evidenciar que a formação de estratégia nas pequenas empresas estudadas varia conforme condições ambientais, estruturais bem como condições pessoais do principal dirigente da organização. Na dimensão empírica, este estudo pode subsidiar ações dos gestores públicos, de associações comerciais.

\section{REFERÊNCIAS}

AMÂNCIO-VIEIRA, S.F.; NEGREIROS, L.F.; MELATTI, G.A.; GIMENEZ, F.A.P. Formação de estratégias em micro e pequenas empresas do comércio de Londrina: uma abordagem sob a perspectiva das configurações. Revista da Micro e Pequena Empresa. v. 7, n. 1. 2013.

BAILEY, A.; AVERY, C. Discovering and defining the process of strategy development. In: AMBROSINI, V.; JOHNSON, G.; SCHOLES, K. (orgs.) Exploring Techniques of Analysis and Evaluation in Strategic Management, Harlow: Prentice-Hall, p. 181-201, 1998.

BERNARDES, Cyro; MARCONDES, Reinaldo. Teoria geral da administração: Gerenciando organizações. São Paulo: Saraiva, 2003.

BERTÉ, E.C.O.P; RODRIGUES, L.C.; ALMEIDA, M.I. A formulação de estratégias para pequenas empresas de base tecnológica. Revista de Administração da UFSM. Santa Maria, v. I, n. 1, p. 116-133, jan./abr. 2008.

CARLAND, James W; CARLAND, J. A.; HOY, F.S. An Entrepreneur index: an empirical validation. Frontiers of Entrepreneurship Research. Boston, v. 25, n.3 p. 244-265, Mar. 1992.

CARLAND, James W; CARLAND, J. A.; HOY, F.S. Who is an Entrepreneur? Is a question worth asking? American Journal of Small Business. V. 15, n. 3, p. 33-39, Spring 1998.

CERTO, Samuel; PETER, J. P.; MARCONDES, Reynaldo. Administração Estratégica:
Planejamento e implantação de estratégias. São Paulo: Pearson, 2010.

CERVO, A. L.; BERVIAN, P. A.. Metodologia científica. 4.ed. São Paulo: Makron Books.1996.

CHÉR, Rogério. A gerência das pequenas e médias empresas: o que saber para administrálas. São Paulo: Maltese,1990.

CHIAVENATO, Idalberto; SAPIRO, Arão. Planejamento Estratégico: Fundamentos e Aplicações. Rio de Janeiro: Campus, 2003.

COCHIA, C. B. R.; MACHADO DA SILVA, C. L. Ambiente, interpretação e estratégia em organizações paranaenses dos setores de vestuários e alimentos. Revista de Administração Contemporânea, v.8, n. especial, 2004.

CONANT, J. S.; MOKWA, M. P.; VARADARAJAN, P. R. Strategic types, distinctive marketing competencies and organisational performance: a multiple measures-based study. Strategic Management Journal, v. 11, p. 365-383, 1990.

COOPER, Donald; SCHINDLER, Pamela. Métodos de Pesquisa em Administração. Porto Alegre: Bookman, 2003.

DRUCKER, P. F. Prática da administração de empresas. São Paulo: Pioneira, 1981.

FECOMERCIO - PR. A Câmara das Mulheres Gestoras e Empreendedoras do Paraná. Curitiba: FECOMERCIO, 2011.

FECOMERCIO - PR. Pesquisa do perfil de empresas do Paraná. Curitiba: FECOMERCIO, 
2010.

GIL, A. C. Como elaborar projetos de pesquisa. São Paulo: Ed. Atlas, 2002

GOMES, D.T.; MUNIZ, R.M.; DIAS, A.T.; GONÇALVES, C.A. Apresentação do processo de formação da estratégia: um estudo de caso em empresa inovadora. Revista de Administração da UFSM. Santa Maria, v. 5, n. 3, p. 413-438, set./dez. 2012.

HAMEL, Gary; PRAHALAD, C. K. Competindo pelo futuro: estratégias inovadoras para obter o controle do seu setor e criar os mercados de amanhã. Rio de Janeiro: Elsevier, 1995.

HARRISON, Jeffrey S. Administração Estratégica de recursos e relacionamentos. Porto Alegre: Bookman, 2005.

HITT, Michael; IRELAND, Duane; HOSKISSON, Robert E. Administração Estratégica: competitividade e globalização. 2. Ed. São Paulo: Cengage Learning, 2008.

INÁCIO JÚNIOR, E.; GIMENEZ, F. A. P. Potencial empreendedor: um instrumento para mensuração. Revista de Negócios, v.9, n.2, abr./jun. 2004.

JOHNSON, G.; SCHOLES, K. (orgs) Exploring Techniques of Analysis and Evaluation in Strategic Management. Harlow: Prentice-Hall, 1998

KWASNICKA, Eunice. Introdução à Administração. Rio de Janeiro: Atlas, 1998.

LONGENECKER, Justin G.... [et al.]. Administração de pequenas empresas. São Paulo: Thomson Learning, 2007.

MARCONDES, Reynaldo; BERNARDES, Cyro. Teoria Geral da Administração. São Paulo: Saraiva, 2003.

MATTAR, F. N. Pesquisa. São Paulo: Atlas, 2001.

MEGGINSON, Leon C. Administração: conceitos e aplicações. São Paulo: Harbra,
1998.

MEYER, A. D.; TSUI, A. S.; HININGS, C. R. Configurational approaches to organizational analysis. Academy of Management Journal, v. 36, n. 6, p. 1175-1195, 1993.

MILES, R.; SNOW, C. C. Organisational strategy, structure and process. London: Mc Graw - Hill, 1978.

MINTZBERG, H. 'Strategy formation: schools of thought', in J.W. Fredrickson (ed.), Perspectives on Strategic Management. New York: Harper \& Row, pp. 105-235, 1990.

MINTZBERG, Henry; AHLSTRAND, Bruce; LAMPEL, Joseph. Safári de Estratégia: Um roteiro pela selva do planejamento estratégico.

2. Ed. Porto Alegre: Bookman, 2000.

MINTZBERG, Henry; QUINN, James B. O Processo da Estratégia. Porto Alegre: Bookman, 2001.

PORTER, Michael E. Estratégia Competitiva: Técnicas para análise de indústrias e da concorrência. Rio de Janeiro: Campus, 1986.

PORTER, Michael E. Quanto menor a empresa mais importante a estratégia. Rio de Janeiro: Campus, 1995.

RICHARDSON, Roberto J. Pesquisa Social: Métodos e Técnicas. 3. Ed. São Paulo: Atlas, 1999.

RUIZ, J. A. Metodologia Científica: guia para eficiência nos estudos. São Paulo: Atlas, 1982.

SANTOS, Rubens da Costa. Manual de gestão empresarial . São Paulo: Atlas, 2007.

SEBRAE. Como abrir seu próprio negócio: Manual prático de iniciação empresarial. Brasília: SEBRAE, 1992, p. 2-12.

SOARES, M.L.; TEIXEIRA, O.R.P.;PELISSARI, A.S. Comportamento organizacional:

Uma aplicação da tipologia de Miles e Snow no setor hoteleiro de Florianópolis, SC. Revista de 
Administração da UFSM. Santa Maria, v. 4, n.1, p. 251-267 mai./ago. 2011.

STONER, James; FREEMAN, Edward. Administração. Rio de Janeiro: LTC, 1994.

TAVARES, Mauro C. Gestão Estratégica. São Paulo: Atlas, 2010.

WESTLEY, F. MINTZBEG, H. Visionary leadership and strategic management, Strategic Management Journal, 10 (special issue): 1732, 1989. 